\title{
Control of Glycolysis in Skeletal Muscle from Fetal Rhesus Monkeys
}

\author{
CLARISSA H. BEATTY, MARTHA K. YOUNG, AND ROSE MARY BOCEK \\ Division of Perinatal Biology, Oregon Regional Primate Research Center, Beaverton, and Department of \\ Biochemistry, University of Oregon Medical School, Portland, Oregon, USA
}

\section{Extract}

In our studies of metabolic control mechanisms in skeletal muscle from rhesus fetus we have determined the tissue levels of the metabolic intermediates and cofactors of the glycolytic pathway and have calculated the mass-action ratios for each reaction. Skeletal muscle from rhesus fetuses (Macaca mulatta), 90-155 days of gestational age, and from adult rhesus monkeys was used in these experiments.

The apparent equilibrium constants for hexokinase and phosphofructokinase (PFK) in these tissues were over 1,000 times larger than the mass-action ratios at all ages studied; the corresponding values for pyruvate kinase were more than 800 times different. The data suggest that these three enzymes are rate-limiting for fetal skeletal muscle as early as $54 \%$ of gestation. The next step was to study some of the numerous factors that modify these nonequilibrium reactions. Increasing the ATP concentration had a marked effect on the PFK activity of both fetal and adult muscle, first increasing and then inhibiting enzyme activity. At maximum PFK activity, the amount of fructose-6- $\mathrm{PO}_{4}(\mathrm{~F} 6 \mathrm{P})$ phosphorylated per $\mathrm{mg}$ of protein was 2-3 times greater in the two fetal than in the adult series. At a concentration of $0.3 \mathrm{mM}$, citrate decreased PFK activity of the 100-day fetal muscle; a further decrease occurred at $1.2 \mathrm{mM}$ citrate. At a citrate level of $0.3 \mathrm{mM}$, the addition of inorganic phosphate $\left(P_{1}\right)$ or cyclic AMP returned $P F K$ activity to the uninhibited levels $(\mathrm{pH} 7.0)$. Relief of ATP inhibition of F6P phosphorylation with $P_{1}$ and cyclic AMP was also observed at pH 7.0 in extracts of 100-day fetal skeletal muscle.

\section{Speculation}

Control of carbohydrate metabolism in the fetus and newborn $(30,31)$ has recently become a point of considerable interest. For example, it is now known that the mammalian fetus possesses an endocrinologic autonomy and many hormones have been identified in the fetal circulation early in gestation. The mere presence of a hormone, however, does not necessarily imply that it is physiologically or biochemically active since tissue responsiveness may not have developed. It is generally agreed that in the adult, one of the primary effects of many hormones is to change the intracellular concentration of cyclic AMP (26). However, for the hormone to have its effect the cell must be capable of responding to such a change. In an earlier paper (7), we suggested that insulin and epinephrine affect carbohydrate metabolism in rhesus fetal muscle by changing the level of cyclic AMP. But even the simplest hormonemediated action has its origin in a chain of events, every link of which must be intact if the system is to work. These considerations are relevant to the perinatal period, for the enzymes in the adult cell are not necessarily present in the corresponding fetal cell (30). Our data provide evidence that as early as midterm the enzyme, PFK, which is generally agreed to be rate-limiting for glycolysis in adult tissues, is also rate-limiting in fetal muscle and is sensitive to changes in the level of effector molecules such as cyclic AMP. These results provide support for the hypothesis that in the overall regulation of glycolysis and the action of such hormones as epinephrine there is no major difference between fetal and adult muscle.

During the last 15 years the scarcity of data published on the metabolism and biochemistry of fetal skeletal muscle contrasts with the amount of similar information on adult muscle. Studies on muscle from fetal rhesus monkeys (Macaca mulatta), which are biologically similar to the human primate, are therefore of particular interest. Although the newborn rhesus monkey appears to be somewhat more advanced physically than the human baby, we have demonstrated that rhesus skeletal muscle shows a pattern of differentiation into fiber types similar to that of the adult muscle at about the same relative gestational age $(73 \%$ of term) as the human muscle ( $75 \%$ of term) (3). Many publications are available on the identification of rate-limiting reactions for the glycolytic pathway in adult skeletal and cardiac muscle $(20,22)$, but similar data on fetal muscle appear to be lacking. Experimental approaches to identifying regulatory enzymes in metabolic pathways include determining mass-action ratios, assaying maximal enzyme activities in vitro, measuring the effects of altered flux rates on the tissue content of pathway intermediates, measuing the rates of product formation from various precursors, and investigating the kinetic and allosteric properties of enzymes. As a result of such studies, much evidence has accrued to implicate the reactions catalyzed by hexokinase, PFK, and pyruvate kinase, as regulatory reactions for glycolysis in adult tissues $(20,22)$.

As a first step in our investigation we determined the levels of all the metabolic intermediates and cofactors in the glycolytic pathway of skeletal muscle from fetal rhesus monkeys and used these data to identify enzymes which catalyze nonequilibrium or possible rate-limiting reactions. The evidence shows that the same enzymes previously reported to be nonequilibrium and rate-limiting in adult skeletal and cardiac muscle are also nonequilibrium and therefore possibly rate-limiting in fetal muscle: hexokinase, PFK, and pyruvate kinase $(22,34)$. We found further evidence for a rate-limiting step at the level of PFK with extracts of fetal muscle. Results similar to ours have been reported for sperm extracts (11).

\section{MATERIALS AND METHODS}

Skeletal muscle from rhesus fetuses ( $M$. mulatta), 90-155 days of gestational age, and adult rhesus monkeys was used in these experiments. The average gestational age in our colony was 165 days. The monkeys were anesthetized with Halothane (2-bromo-2chloro-1,1,1-trifluoroethane (1\% or less) in a mixture of $75 \%$ oxygen and $25 \%$ nitrous oxide or Ketalar (dl-2-( $O$-chlorophenyl)-2-(methylamino)cyclohexane hydrochloride), $5 \mathrm{mg} / \mathrm{kg}$. Samples of muscle were taken from the upper arrn and thigh of fetuses and from the sartorius muscle of adults. For the determination of mass-action ratios, the muscle was carefully stripped of fat and connective tissue in situ and a sample was then excised and frozen within $3 \mathrm{sec}$ in a Wollenberger clamp at liquid nitrogen temperature. The muscle was then wrapped in aluminum foil and stored at liquid nitrogen temperature. 
The frozen biopsy was prepared for analysis as described previously (4). and the glycolytic intermediates were assayed with a Perkin-Elmer 203 fluorescent spectrometer with appropriate coupling enzymes by the disappearance of added NADH or the formation of NADPH from added NADP as described by Maitra and Estabrook (18) and Lowry and Passonneau (16) with modifications. Recovery of known quantities of glycolytic intermediates was usually good and varied between $85 \%$ and $100 \%$. If duplicate determinations did not agree within $10 \%$, additional determinations were done. ATP, ADP, and AMP were determined by a modification of the methods of Stanley and Williams (32) and Johnson et al. (12). Adenine nucleotides in $\mathrm{HClO}_{4}$, which do not keep well at $-20^{\circ}(35)$, are stable for at least 1 month at liquid nitrogen temperature $\left(-200^{\circ}\right)$. Orthophosphate was determined on the neutralized $\mathrm{HClO}_{4}$ supernatant (17). The value of $21 \%$ for the extracellular space in rhesus muscle was determined previously in our laboratory with $\left[U-{ }^{14} \mathrm{C}\right]$ inulin $(5)$. The volume of the intracellular water was calculated as the difference between the total water content and the inulin space. With these data, mass-action ratios were calculated as described by Newsholme and Start (Reference 22 , p. 30). Since experimental determination of the content of 1,3-diphosphoglycerate in tissues is difficult, it is more convenient to combine the reactions producing and utilizing this compound and to calculate the mass-action ratio for the combined glyceraldehyde phosphate dehydrogenase and phosphoglycerate kinase reaction (Reference 22, p. 141).

For the experiments on extracts of skeletal muscle, the tissue was collected under the same conditions as previously described, dissected free of adipose and connective tissue, immediately rinsed in ice-cold $150 \mathrm{mM} \mathrm{KCl}$, and freeze-clamped. A 0.5-1.0-g sample of the frozen muscle was placed on top of $0.5 \mathrm{ml}$ frozen medium (80 $\mathrm{mM} \mathrm{KCl}, 80 \mathrm{mM} \mathrm{N}$-tris(hydroxymethyl)methyl-2-aminoethane sulfonic acid (TES), $\mathrm{pH} 7.4$, at room temperature) in a glass tube packed in dry ice and chopped finely with a scalpel. A small amount of cold homogenizing medium was added and the chopped tissue was allowed to thaw in a slurry of cold medium. The sample was diluted to make a $10 \%$ mixture (weight to volume) and homogenized in a Polytron (PT20 ST) for $5 \mathrm{sec}$ at $4.0^{\circ}$. The homogenate was centrifuged for $30 \mathrm{~min}$ at $21,000 \times g\left(2^{\circ}\right)$, the protein level of the supernatant was quickly determined by a modification of Lowry's method (14), and the protein concentration was adjusted to the desired level. This extract is similar to a heart extract studied by Mansour (19) and extracts of several other tissues such as sperm $(11,21)$. One-half milliliter of the muscle extract was added to $0.5 \mathrm{mI}$ incubation medium pH 7.0 or 8.2 at $37^{\circ}$ (final concentrations in the tube are $80 \mathrm{mM} \mathrm{TES}, 80 \mathrm{mM} \mathrm{KCl}$, 1-2 mM NAD, $0.2 \mathrm{mM} \mathrm{MgCl}_{2}, 0.08-3.0 \mathrm{mM} \mathrm{F6P),} \mathrm{ATP} \mathrm{was}$ added as indicated, and the mixture was incubated in a Dubnoff shaker at $37^{\circ}$. The reaction was stopped by the addition of $30 \mu 1$ $60 \% \mathrm{HClO}_{4}$. In the series where the level of ATP in the incubation medium was increased, the $\mathrm{MgCl}_{2}$ was maintained at equimolar levels; when citrate was added, the $\mathrm{MgCl}_{2}$ was maintained at concentrations $0.1 \mathrm{mM}$ higher than the citrate concentration. The value for $\mathrm{F} 6 \mathrm{P}$ phosphorylated was obtained by subtracting the levels of glucose-6-P and F6P left after incubation with exogenous F6P from the original values in the incubation medium.

\section{RESULTS}

The enzymes that catalyze equilibrium reactions cannot control the overall rate of flux in metabolic pathways under physiologic conditions. Therefore, the first step in identifying rate-limiting reactions is to identify the enzymes that catalyze reactions far removed from equilibrium. This can be done by measuring the tissue levels of all the metabolic intermediates and cofactors of a pathway and calculating the mass-action ratios for each reaction. If the apparent equilibrium constant is similar to the mass-action ratio, an equilibrium reaction is indicated. If the apparent equilibrium constant is larger than the mass-action ratio, a nonequilibrium or possible rate-limiting reaction is indicated. All rate-limiting enzymes must be nonequilibrium, but all nonequilibrium enzymes are not necessarily rate-limiting. According to Rolleston (27), if the apparent equilibrium constant is at least 20 times larger than the mass-action ratio, the reaction is probably nonequilibrium or rate limiting.

The values for the mass-action ratios for the glycolytic pathway of fetal and adult skeletal muscle and for the apparent equilibrium constants at pH 7.4 are shown in Table 1 . There is no significant difference between the fetal and adult values. The tissue levels for the glycolytic intermediates and cofactors from which the massaction ratios are calculated are shown in Table 2 . The apparent equilibrium constants for hexokinase and PFK in these tissues were over 1,000 times larger than the mass-action ratios at all ages studied; the corresponding values for pyruvate kinase were more than 800 times different. These data suggest that as early as $54 \%$ of gestation these three enzymes are rate-limiting for glycolysis in fetal skeletal muscle. However, it is difficult to assess the nature of rate-limiting enzymes in a metabolic pathway from calculated apparent equilibrium constants and mass-action ratios since the conditions under which these values are obtained may not reflect the situation in vivo. Since no experimental values for 1,3-diphosphoglycerate levels are available, the mass-action ratios of glyceraldehyde-P dehydrogenase and phosphoglycerate kinase cannot be calculated individually. There is evidence that this overall reaction may be a nonequilibrium reaction in other tissues such as heart and Taenia coli $(4,34)$. However, the apparent equilibrium constants

Table I. Comparison of apparent equilibrium constants with mass-action ratios for glycolytic reactions of fetal and adult skeletal muscle

\begin{tabular}{|c|c|c|c|c|}
\hline & $\begin{array}{l}\text { Apparent equilibrium } \\
\text { constant }^{1}\end{array}$ & \multicolumn{3}{|c|}{ Mass-action ratios } \\
\hline Phosphoglucoisomerase & $0.4-0.5$ & 0.30 & 0.21 & 0.18 \\
\hline Phosphofructokinase ${ }^{2}$ & $1 \times 10^{3}$ & $6 \times 10^{-2}$ & $8 \times 10^{-2}$ & 0.20 \\
\hline Aldolase $(\mathrm{M})$ & $7-13 \times 10^{-5}$ & $1.3 \times 10^{-5}$ & $0.7 \times 10^{-5}$ & $1.0 \times 10^{-5}$ \\
\hline Phosphoglycerate mutase & $0.1-0.2$ & 0.2 & 0.5 & 0.5 \\
\hline Enolase & $2.8-4.6$ & 1.0 & 2.0 & 1.7 \\
\hline Pyruvate kinase $^{2}$ & $2-20 \times 10^{3}$ & 11.4 & 8.1 & 12.6 \\
\hline
\end{tabular}

${ }^{1}$ Values from Newsholme and Start (22) and Williamson (34).

${ }^{2}$ Rate-limiting.

${ }^{3}$ Mass-action ratios calculated according to Newsholme and Start (Reference 22, p. 140). 
Table 2. Levels of glycolytic intermediates and cofactors in skeletal muscle from fetal and adult rhesus monkeys ${ }^{1}$

\begin{tabular}{lccc}
\hline & \multicolumn{3}{c}{ nmol/g wet weight } \\
\cline { 2 - 4 } & Fetal & Fetal \\
& $(90 \text { day })^{2}$ & $(150 \text { day })^{2,3}$ & Adult $^{4}$ \\
\hline Glucose $^{5}$ & 4,839 & 1,227 & 664 \\
Glucose-6-P $_{\text {Fructose-6-P }}$ & 104 & 436 & 193 \\
Fructose-1,6-diphosphate & 30.9 & 89.6 & 35.5 \\
Glyceraldehyde-P & 15.0 & 41.0 & 45.2 \\
Dihydroxacetone-P & 12.8 & 11.2 & 18.8 \\
3-Phosphoglyceric acid & 14.6 & 23.8 & 23.2 \\
2-Phosphoglyceric acid & 24.3 & 20.3 & 20.0 \\
Phosphoenolpyruvic acid & 5.3 & 10.8 & 9.8 \\
Pyruvate & 5.4 & 9.9 & 16.7 \\
Lactate & 10.8 & 13.8 & 18.3 \\
Inorganic phosphate & 3,659 & 4,985 & 1,356 \\
ATP & 3,563 & 4,766 & 3,849 \\
ADP & 1,618 & 3,092 & 4,003 \\
AMP & 190 & 535 & 639 \\
Adenylate energy charge & & 6 & 14 \\
\hline
\end{tabular}

${ }^{1}$ Values are averages of duplicate determinations on muscle samples from two rhesus monkeys.

${ }^{2}$ Biceps, triceps, and thigh muscle.

${ }^{3}$ Single monkey, duplicate samples.

${ }^{4}$ Sartorius.

${ }^{5}$ Intracellular concentration.

${ }^{6}$ Too low to measure.

${ }^{7}(\mathrm{ATP}+0.5 \mathrm{ADP})-\mathrm{ATP}+\mathrm{ADP}+\mathrm{AMP}(1)$.

for the combined reaction of the two enzymes as well as the remaining reactions in the glycolytic pathway for fetal and adult muscle appear to be equilibrium reactions since the apparent equilibrium constants are less than 20 times larger than the mass-action ratios (Table 1).

Although the ATP levels (nanomoles per $g$ wet wt) are lower in the 90-day fetal muscle (Table 2) than in the adult muscle, the energy charge, as defined by Atkinson (1) (ATP + 0.5 ADP-ATP $+\mathrm{ADP}+\mathrm{AMP})$, is similar to that in the adult series and greater than 0.8 . This value for the adenylate energy charge represents a stable metabolic state and is presumed to indicate a physiologic situation in the cell (20). Furthermore, when the ATP levels were calculated on a per $\mathrm{mg}$ of nitrogen basis, they were $144 \mathrm{nmol}$ $\mathrm{ATP} / \mathrm{mg} \mathrm{N}$ for the adult and $141 \mathrm{nmol} \mathrm{ATP} / \mathrm{mg} \mathrm{N}$ for the fetal series.

The next step was to study sume of the numerous factors that might modify these nonequilibrium or rate-limiting reactions, including ATP, citrate, $\mathrm{P}_{1}$, and cyclic AMP. In Figure $1 A$ we have compared the effect of increasing levels of exogenous ATP on the amount of F6P converted to fructose-1,6-diphosphate (FDP) by extracts of fetal and adult muscle $(\mathrm{pH} \mathrm{7.0)}$. The endogenous levels of ATP were less than $0.02 \mathrm{mM}$. The level of $P_{1}$ was relatively constant between 0.2 and $0.3 \mathrm{mM}$. At $\mathrm{pH} 7.0$ ATP had a marked effect on the PFK activity of both fetal and adult muscle, first increasing and then decreasing enzyme activity. This biphasic response of PFK from adult tissues to increasing levels of ATP (at low $\mathrm{pH}$ values) has been reported by others $(10,15,20)$. At the lower levels of ATP, the activity of PFK was similar in the fetal and adult muscle extracts; however, the PFK activity of the adult series peaked at $0.1 \mathrm{mM} \mathrm{ATP}$, the neonatal series at $0.15 \mathrm{mM}$ ATP, the 150-day series at $0.3 \mathrm{mM}$, and the 100 -day at $0.6 \mathrm{mM}$. At maximum PFK activity the amount of F6P phosphorylated per $\mathrm{mg}$ of protein in the fetal series was $2-3$ times greater than that in the adult series. If the intracellular levels of ATP in vivo are estimated from the values found in Table 2, the lowest concentra- tion is $2 \mathrm{mM}$; this level is inhibitory in our in vitro system (Fig. $1 A$ ). The intracellular $\mathrm{P}_{1}$ is about $4 \mathrm{mM}$ and the cyclic AMP 0.6 $\mu \mathrm{M}$. Presumably the operation of the glycolytic pathway in both the fetal and adult muscle depends on the presence of ligands such as $P_{1}$ that are capable of deinhibiting PFK when high concentrations of ATP are present.

When the concentration of F6P was increased the total amount converted to FDP increased in a linear fashion (Fig. 2); however, there was a marked change in the effect of ATP on PFK activity. As the F6P substrate level increased, the inhibitory effect at $6 \mathrm{mM}$ ATP decreased from $100 \%$ at $1 \mathrm{mM} \mathrm{F6P}$ to less than $10 \%$ at 3 $\mathrm{mM}$.

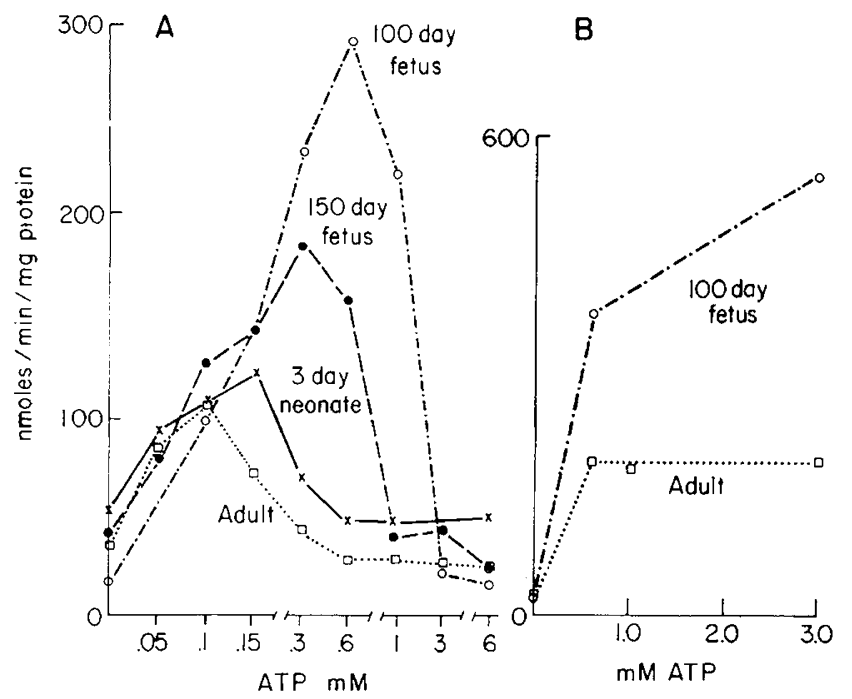

Fig. 1. A: effect of increasing levels of ATP on the nanomoles of fructose-6-PO , converted to fructose-1,6-diphosphate by extracts of skeletal muscle from rhesus monkeys at different stages of development. Incubation time $4 \mathrm{~min}, 0.6-0.7 \mathrm{mg}$ protein $/ \mathrm{ml}$ incubation medium. The incubation medium was $80 \mathrm{mM} \mathrm{N}$-tris(hydroxymethyl)methyl-2-aminoethanesulfonic acid, $80 \mathrm{mM} \mathrm{KCl}, 2 \mathrm{mM}$ NAD, $0.2 \mathrm{mM} \mathrm{MgCl}_{2}, 1 \mathrm{mM}$ fructose-6- $\mathrm{PO}_{4}$, ATP added as indicated $\left(\mathrm{MgCl}_{2}\right.$ maintained at equimolar concentrations), $200 \mathrm{mg} / 100 \mathrm{ml}$ bovine serum albumin, $\mathrm{pH} 7.0$, at $37^{\circ}$. Endogenous levels of ATP in the medium were $0.02 \mathrm{mM}$ or less and $P_{i}$ was 0.2 to $0.3 \mathrm{mM}$. Duplicate incubations, two monkeys in each group except for the 3-day-old neonate group which had one monkey. $B$ : effect of increasing levels of ATP on the nanomoles of fructose-6- $\mathrm{PO}_{4}$ converted to fructose-1,6-diphosphate. Experimental conditions as in $A, 3 \mathrm{mM}$ fructose-6- $\mathrm{PO}_{4}, \mathrm{pH} 8.2$, at $37^{\circ}$.

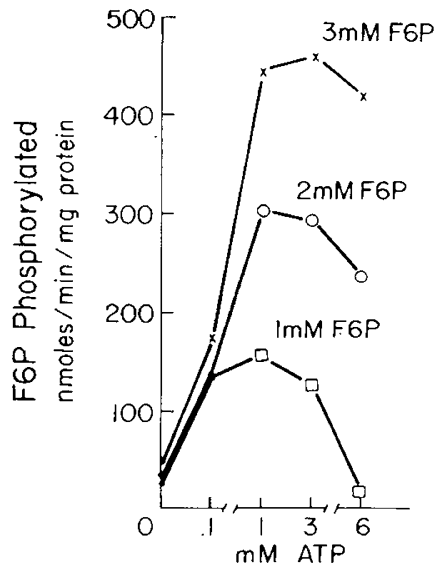

Fig. 2. Effect of increasing levels of fructose-6-PO $(F 6 P)$ on the inhibitory effect of high levels of ATP in an extract of skeletal muscle from a 100-day fetal rhesus monkey. Experimental conditions are as described in legend to Figure 1 with an incubation time of $10 \mathrm{~min}$. 


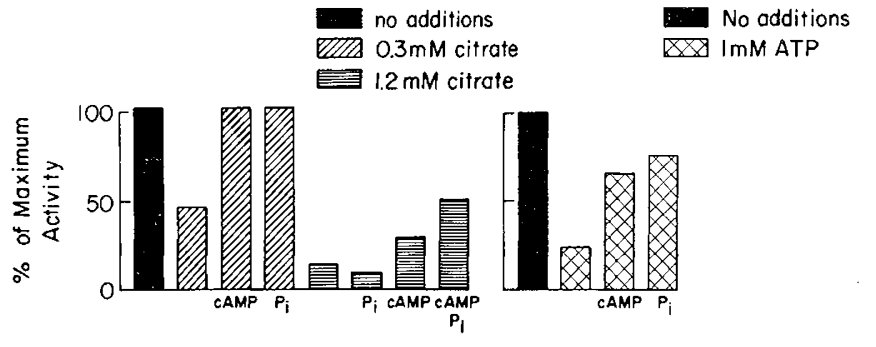

Fig. 3. Relief by $0.1 \mathrm{mM}$ cyclic AMP and $1.0 \mathrm{mM} \mathrm{P}_{\mathrm{i}}$ of citrate and ATP inhibition of fructose-6-PO, phosphorylation in extracts of 100-day fetal muscle. Experimental conditions as in Figure 1.

Citrate, at a concentration of $0.3 \mathrm{mM}$, decreased PFK activity of the 100-day fetal muscle with a further decrease at $1.2 \mathrm{mM}$ citrate (Fig. 3A). At a citrate level of $0.3 \mathrm{mM}$, the addition of inorganic phosphate $\left(\mathrm{P}_{1}\right)$ or cyclic AMP returned PFK activity to the uninhibited levels $(\mathrm{pH} 7.0)$. At $1.2 \mathrm{mM}$ citrate the relief of inhibition with cyclic AMP and $\mathrm{P}_{1}$ was incomplete (Fig. $3 A$ ). Some inhibition of PFK activity, about $24 \%$, was observed at $0.15 \mathrm{mM}$ citrate. Relief of ATP inhibition of F6P phosphorylation with $P_{1}$ and cyclic AMP was also observed at $\mathrm{pH} 7.0$ in extracts of 100-day fetal skeletal muscle (Fig. $3 B$ ).

Since cyclic AMP is an active deinhibitor of fetal PFK and the level of cyclic AMP is higher in fetal than in adult skeletal muscle $(7,8)$, we measured the relative activities of PFK in the two series under conditions ( $\mathrm{pH} 8.2$ ) which would minimize the stimulating effect of cyclic AMP. With mammalian PFK's the enzyme generally loses its susceptibility to regulation as the $\mathrm{pH}$ increases above $7.6(6)$. At pH 8.2 the inhibitory effect of ATP is eliminated (Fig. $1 B$ ) and one would expect a minimal increase in activity with effector molecules such as cyclic AMP (20). However, fetal PFK activity is still about three-fold greater than the adult activity at this high $\mathrm{pH}$ (Fig. $1 B$ ).

A specific activator (nonallosteric) or activators for PFK may be present in fetal muscle or a specific inhibitor or inhibitors in adult muscle. To test this possibility, we combined samples of homogenate from fetal and adult muscle in a ratio of $1: 1$. The activity in the mixture was proportional to the activity in the original extracts (Table 3)

\section{DISCUSSION}

The mass-action ratios for the glycolytic pathway in fetal and adult muscle are alike and are fairly similar to those reported by Newsholme and Start (22) for various other adult tissues such as heart and brain. This emphasizes the basic metabolic similarity of different tissues. Our main problem was to determine how early in gestation do the enzymes catalyzing the nonequilibrium reactions described for adult muscle (hexokinase, PFK, and pyruvate kinase) also catalyze nonequilibrium reactions in developing muscle. Apparently these nonequilibrium reactions can be identified as soon as sufficiently large samples of muscle are available for analysis.

Phosphofructokinase is a key enzyme in the regulation of glycolysis in various adult tissues, e.g., heart and skeletal muscle, brain, liver, erythrocytes, and sperm (20) and in the regulation of its activity by interaction with various compounds, represets a complex enzyme. This complexity lies in the fact that in addition to its multimolecular forms it is affected by a multiplicity of ligands. Furthermore, its kinetics are markedly influenced by $\mathrm{pH}$. At 8.2 , PFK exhibits the Michaelis-Menten type of kinetics, at pH 6.9 typical allosteric kinetics. The sensitivity of PFK to effector molecules varies in different tissues such as liver and skeletal muscle (20). Although ATP has a biphasic effect on muscle PFK activity at all ages studied, the sensitivity of this enzyme to ATP appears to increase as development proceeds (Fig. 1 $A$ ). The younger the muscle studied the higher the level of ATP needed for maximum activity. Mansour $(19,20)$ has reported that increasing the level of F6P decreases the sensitivity of semipurified PFK from guinea pig heart to ATP. As we increased the concentration of F6P in the incubation medium, the concentration of ATP necessary to inhibit the enzyme also increased.

ATP appears to be the most critical of the ligands which modify PFK. This is due to several factors. ATP is present in most tissues at relatively high concentrations, and other modifiers such as $P_{1}$ activate PFK mainly by relieving ATP inhibition (20). In fetal and adult rhesus skeletal muscle, the intracellular concent ration of $\mathrm{F} 6 \mathrm{P}$ was estimated to be about $0.04-0.11 \mathrm{mM}$ and the concentration of ATP greater than $2 \mathrm{mM}$, assuming uniform distribution in intracellular water. Thus, at this low F6P level, the ATP concentration in the skeletal muscle, like that in rat heart $(25)$, is high enough to inhibit glycolysis markedly unless there is considerable deinhibition. Cyclic AMP levels are probably too low to influence the PFK activity unless there is compartmentalization.

We have already demonstrated that the concentration of cyclic AMP is higher in fetal than in adult skeletal muscle $(7,8)$. Since the level of ATP and F6P at all ages is such as to ensure greater inhibition of PFK, the greater PFK activity in fetal compared with adult muscle may be due to relief of this inhibition by the higher level of cyclic AMP in the fetal tissue. At pH 8.2, cyclic AMP does not stimulate PFK activity (19). Therefore, the fact that the difference between fetal and adult PFK activity is similar at $\mathrm{pH} 8.2$ and $\mathrm{pH} 7.0$ is evidence that effector molecules such as cyclic AMP do not account for this difference. Furthermore, a 1:1 mixture of extracts of fetal and adult muscle yields an average PFK activity proportional to that in the original extracts both at $\mathrm{pH} 7.0$ and 8.2. This is additional evidence that the intrinsic activity of fetal PFK is higher than that of adult and concurs with previous data which demonstrate that the $\mathrm{QO}_{2}$ values, $\mathrm{CO}_{2}$ production, glucose uptake, and lactate and pyruvate production (with noncollageous protein as reference base) is higher in 100-day fetal muscle than in adult muscle (2).

Citrate has long been known to be a potent inhibitor of PFK in skeletal muscle from adult animals and $P_{i}$ was shown to be capable of relieving this inhibition (23). Since then, this observation has been verified in many tissues (20). However, to our knowledge, no one has studied the effect of citrate on fetal muscle metabolism. In this study, $0.3 \mathrm{mM}$ citrate markedly inhibited the phosphorylation of F6P to FDP by extracts of muscle from 100-day fetal rhesus monkeys (Fig. 3A). Glycolysis was maximally inhibited by a concentration of $0.3-0.5 \mathrm{mM}$ citrate. As in adult tissues, cyclic AMP and $P_{1}$ relieved this inhibition in extracts of 100-day fetal muscle. In view of the glucose-fatty acid cycle hypothesis originally proposed by Randle et al. (24), the inhibition of glycolysis by citrate is important. According to Randle's hypothesis, the increased availability of fatty acids and ketone bodies for oxidation in diabetes causes an increase in citric acid cycle activity, which in

Table 3. Total phosphofructokinase (PFK) activity in a $1: 1$ mixture of muscle extracts from 100-day fetus and adult rhesus monkey ${ }^{1}$

nmol fructose-6-P phosphorylated/

$\mathrm{min} / \mathrm{mg}$ protein

\begin{tabular}{cccc}
\hline & $\mathrm{pH} 7.0$ & $\mathrm{pH} \mathrm{8.2}$ \\
\hline \multirow{2}{*}{$\begin{array}{c}\text { Observed } \\
\text { value }\end{array}$} & $\begin{array}{c}\text { Calcu- } \\
\text { lated } \\
\text { value }\end{array}$ & $\begin{array}{c}\text { Observed } \\
\text { value }\end{array}$ & $\begin{array}{c}\text { Calcu- } \\
\text { lated } \\
\text { value }\end{array}$ \\
\hline
\end{tabular}

\begin{tabular}{|c|c|c|c|c|}
\hline \multicolumn{5}{|l|}{ Control } \\
\hline Fetal & 481 & & 550 & \\
\hline Adult & 100 & & 190 & \\
\hline $\begin{array}{l}\text { Combined } 1: 1 \text { (fe- } \\
\text { tal:adult) }\end{array}$ & 301 & 290 & 386 & 370 \\
\hline
\end{tabular}

${ }^{1}$ Experimental conditions are as in Figure 1 with $3 \mathrm{mM}$ fructose-6-P, 3 mM ATP (equimolar $\mathrm{MgCl}_{2}$ ), and an incubation time of $5 \mathrm{~min}$. 
turn increases the citrate level in the muscle and decreases glucose uptake and utilization. So far, this glucose fatty acid cycle theory has been verified only in adult cardiac muscle and perhaps diaphragm, specialized muscles that represent only about $1 \%$ of the body weight (28). When applied to a tissue such as skeletal muscle, which represents such a large percentage of total body weight $(20-25 \%$ in the fetal and $40-45 \%$ in the adult rhesus monkey), this hypothesis is of considerable physiologic importance.

The mass-action ratio for pyruvate kinase in fetal and adult muscle indicates a reaction far removed from equilibrium. There have been far fewer studies on this reaction than on PFK, although pyruvate kinase shares some of the regulatory properties of PFK. The maximum activity of pyruvate kinase is so much higher in adult cardiac and skeletal muscle than that of PFK (22) that its activity would have to be markedly decreased to affect glycolysis. However, creatine phosphate, ATP, and phenylalanine inhibit pyruvate kinase and anoxia doubles the activity in terms of flux ( 9 , $13,33,34)$. Further work is needed to determine whether some of the regulatory effects on glycolysis in skeletal muscle in vivo are exerted at the level of pyruvate kinase. However, pyruvate kinase cannot regulate glucose uptake; its inhibition would only cause the accumulation of glycolytic intermediates between fructose diphosphate and phosphoenolpyruvate (22).

Reverse glycolysis is probably not a significant metabolic pathway in these muscle extracts. Although some fructose diphosphatase is found in white skeletal muscle, the levels are too low to be detected in red skeletal muscle, cardiac muscle, or smooth muscle (22). Stiffel et al. (29) found that the activity of PFK in rat muscle was 40 times higher than that of fructose diphosphatase. We know of no data on fetal muscle.

\section{SUMMARY}

In our studies of metabolic control mechanisms in skeletal muscle from the rhesus fetus, we have so far determined the tissue levels of the metabolic intermediates and cofactors of the glycolytic pathway and have calculated the mass-action ratio for each reaction. At midterm, the apparent equilibrium constants in fetal muscle were over 800 times larger than the mass-action ratios for hexokinase, PFK, and pyruvate kinase, evidence that these three enzymes can be regulatory for glycolysis early in development. The remaining reactions in the glycolytic pathway were either at equilibrium or close to equilibrium and therefore cannot be regulatory.

The phosphorylation of F6P by a cell-free extract of fetal and adult muscle was also studied. At $\mathrm{pH} 7.0$, increasing the level of ATP in the incubation medium increased and then decreased the phosphorylation of F6P to FDP (PFK activity). Increasing the concentration of F6P decreased the sensitivity of PFK to increasing levels of ATP. Both cyclic AMP and $P_{1}$ relieved ATP inhibition of PFK in extracts of 100-day fetal muscle. Citrate inhibited PFK activity in the 100-day series and this inhibition was also relieved by cyclic AMP and $P_{1}$. These effects are typical of the reactions of semipurified preparations of PFK from many adult tissues.

At $\mathrm{pH} 7.0$ and $\mathrm{pH} 8.2$ the activity of PFK was 3-5 times greater in fetal muscle extracts (midterm) than in adult; this difference was present but less pronounced close to term and even less in the neonate.

\section{REFERENCES AND NOTES}

1. Atkinson, D. E.: Adenine nucleotides as stoichiometric coupling agents in metabolism and as regulatory modifiers. In: H. J. Vogel: Metabolic Pathways, Vol. 5, p. I (Academic Press, New York, 1971)

2. Beatty, C. H., Basinger, G. M., and Bocek, R. M.: Oxygen consumption and glycolysis in fetal, neonatal and infant muscle of the rhesus monkey. Pediatrics, 42: 5 (1968).

3. Beatty, C. H., Basinger, G. M., and Bocek, R. M.: Differentiation of red and white fibers in muscle from fetal, neonatal and infant rhesus monkeys. J. Histochem. Cytochem., 15: 93 (1967).

4. Beatty, C. H., Bocek, R. M.. and Young, M. K.: Glycolytic control mechanisms in myometrium from pregnant rhesus monkeys. Biol. Reprod., 12: 408 (1975).
5. Beatty, C. H., Curtis, S., Young, M. K., and Bocek, R. M.: Oxidation of amino acids by red and white muscle fiber groups. Amer. J. Physiol., 227: 268 (1974).

6. Bloxham, D. P., and Lardy, H. A.: Phosphofructokinase. In: P. D. Boyer: The Enzymes, Vol 8, Part A, p. 239 (Academic Press, New York, 1973)

7. Bocek, R. M., Young, M. K., and Beatty, C. H.: Effect of insulin and epinephrine on the carbohydrate metabolism and adenylate cyclase activity of rhesus fetal muscle. Pediat. Res., 7: 787 (1973).

8. Bocek, R. M., Beatty, C. H., and Young, M. K.: Cyclic AMP in developing muscle of the rhesus monkey. Effect of prostaglandin $\mathrm{E}_{2}$. Biol. Neonate (In press).

9. Carminatti, H. Jiménez de Asúa, L., Leiderman, B., and Rozengurt, E.: Allosteric properties of skeletal muscle pyruvate kinase. J. Biol. Chem., 246: $7284(1971)$

10. Hoskins, D. D., and Stephens, D. T.: Regulatory properties of primate sperm phosphofructokinase. Biochim. Biophys. Acta, 191: 292 (1969).

11. Hoskins, D. D., Stephens, D. T., and Casillas, E. R.: Enzymic control of fructolysis in the primate sperm. Biochim. Biophys. Acta 237: 227 (1971).

12. Johnson, R. A., Hardman, J. G., Broadus, A. E., and Sutherland, E. W.: Analysis of adenosine $3^{\prime}, 5^{\prime}$-monophosphate with luciferase luminescence. Anal. Biochem., 35:91 (1970)

13. Kemp, R. G.: Inhibition of muscle pyruvate kinase by creatine phosphate. J. Biol. Chem., 248: 3963 (1973).

14. Lowry, O. H., Rosebrough, N. J., Farr, A. L., and Randall, R. J.: Protein measurement with the Folin phenol reagent. J. Biol. Chem., 193: 265 (1951)

15. Lowry, O. H., and Passonneau, J. V.: Kinetic evidence for multiple binding sites on phosphofructokinase. J. Biol. Chem., 241: 2268 (1966).

16. Lowry, O. H., and Passonneau, J. V.: A Flexible System of Enzymatic Analysis (Academic Press, New York, 1972).

17. Lowry, O. H., and Lopez, J. A.: The determination of inorganic phosphate in the presence of labile phosphate esters. J. Biol. Chem., 162: 421 (1946).

18. Maitra, P. K., and Estabrook, R. W.: A fluoromatic method for the enzymic determination of glycolytic intermediates. Anal. Biochem., 7: 472 (1964).

19. Mansour, T. E.: Studies on heart phosphofructokinase: Purification, inhibition, and activation. J. Biol. Chem., 238: 2285 (1963).

20. Mansour, T. E.: Phosphofructokinase. In: B. L. Horecker and E. R. Stadtman: Current Topics in Cellular Regulation, Vol. 5, p. 1 (Academic Press, New York, 1972).

21. Nakatsu, K., and Mansour, T. E.: Reversible changes in the stability of phosphofructokinase in rat diaphragm. Biochem. Biophys. Res. Commun. 60: 1331 (1974).

22. Newsholme, E. A., and Start, C.: Regulation of carbohydrate metabolism in muscle. In: Regulation in Metabolism, p. 88 (John Wiley and Sons, New York, 1973).

23. Passonneau, J. V., and Lowry, O. H.: P-fructokinase and the control of the citric acid cycle. Biochem. Biophys. Res. Commun. 13: 372 (1963).

24. Randle, P. J., Garland, P. B., Hales, C. N., and Newsholme, E. A.: The glucose fatty-acid cycle. Lancet, $i: 785$ (1963).

25. Regan, D. M., Young, D. A. B., Davis, W. W., Jack, J., Jr., and Park, C. R.: Adjustment of glycolysis to energy utilization in the perfused rat heart. J. Biol. Chem., 239: 381 (1964).

26. Robison, G. A., Butcher, R. W., and Sutherland, E. W.: Cyclic AMP (Academic Press, New York, 1971).

27. Rolleston, F. S.: A theoretical background for the use of measured concentrations of intermediates in study of the control of intermediary metabolism. In: Ed. B. L. Horecker and E. R. Stadtman: Current Topics in Cellular Regulation, Vol. 5, p. 47 (Academic Press, New York, 1972).

28. Ruderman, N. B., Toews, C. J., and Shafrir, E.: Role of free fatty acids in glucose homeostasis. Arch. Int. Med., 123: 299 (1969).

29. Stiffel, F. B., Tauton, O. D., Greene, H. L., and Herman, R. H.: Rapid reciprocal changes in rat tissue enzyme activities following epinephrine injection. J. Biol. Chem., 249: 7240 (1974).

30. Shelley, H. J., Bassett, J. M., and Milner, R. D. G.: Control of carbohydrate metabolism in the fetus and newborn. Brit. Med. Bull., 31: 37 (1975).

31. Spellacy, W. N.: Maternal and fetal metabolic interrelationships. In: H. W. Sutherland and J. M. Stowers: Carbohydrate Metabolism in Pregnancy and the Newborn, (Churchill Livingstone, Edinburgh, 1975).

32. Stanley, P. E., and Williams, S. G.: Use of the liquid scintillation spectrometer for determining adenosine triphosphate by the luciferase enzyme. Anal. Biochem., 29: 381 (1969).

33. Tanaka, T., Harano, Y., Sue, F., and Morimura, H.: Crystallization, characterization and metabolic regulation of two types of pyruvic kinase isolated from rat tissues. J. Biochem., 62: 75 (1967)

34. Williamson, J. R.: Glycolytic control mechanism. II. Kinetics of intermediate changes during aerobic-anoxic transition in perfused rat heart. J. Biol. Chem., 241: 5026 (1966)

35. Wood, T.: Breakdown of adenosine triphosphate by muscle preparations in the presence of perchloric acid. Anal. Biochem., 43: 107 (1971).

36. Publication No. 811 of the Oregon Regional Primate Research Center, supported in part by Grant RR-00163 of the National Institutes of Health.

37. This investigation was supported in part by Public Health Service Grants HD-06069 and HD-06425 and General Research Support Grant RR-05694, National Institute of Child Health and Human Development, and by the Muscular Dystrophy Association of America, Inc.

38. Requests for reprints should be addressed to: C. H. Beatty, Ph.D., Oregon Regional Primate Research Center, 505 N.W. 185th Ave., Beaverton, Ore. 97005 (USA)

39. Accepted for publication October 15, 1975 